\title{
Output Voltage and Current Ripples performance Examination in Two Bus system with Boost converters fed UPQC and reduction
}

\author{
G.V.Prasanna Anjaneyulu, R. Hothri, Sk. Johny Begam, P. Bhramaramba Vathi, K.Chandrika, \\ T.Venkatesh
}

\begin{abstract}
This paper presents UPQC with various Boost converter device for reduce the receiving end voltage and sending end current ripples of existed conventional multi bus system. Unified Power Quality Conditioner (UPQC) is a dynamic FACT device transmission system. The UPQC configuration has the capabilities of these two devices, Voltage Regulators, Active Filters. It is noticed that the multi bus system with UPQC minimises the system losses. So UPQC increases the multi bus system performance. This paper also presents the suitable boost converter between PV system and UPQC capacitor to charge the capacitor. Here principle of operation and its implementation of boost converters for multi bus system are presented. Three various types of boost converters those are High Step Up type Boost Converter (HSBC), Double Inductor type Boost Converter $(D I B C)$ and Inter Connected Boost Converter (ICBC) are used for comparative analysis. The comparison is done in boost converter output voltage, input current and those ripples, also transmitting real power and reactive powers. With MATLAB/SIMULINK results, Inter Connected Boost Converter (ICBC) is selected as best converter device in between Photo voltaic system, capacitor of $U P Q C$.
\end{abstract}

Keywords : Multibus system, Boost Converters, Voltage Ripple, Current Ripple.

\section{CONFIGURATION \& INTRODUCTION TO UPQC}

The main functional objective of electric utility is supply its customers/loads at a pure sinusoidal voltage of fairly constant amplitude and frequency without any distortions. The synchronous generators produce the electric power at very close to a pure sinusoidal signal with constant amplitude. The intension, implementation, and function of organizational and commercial power systems need several concepts to assist in the calculation of the dynamic system performance with transient conditions, reliability of system, stability, security and the capability to increase with production and also functional needs.

Nomenclature

HSBC High Step Up type Boost Converter

Revised Manuscript Received on September 22, 2019.

* Correspondence Author

Dr. G.V.Prasanna Anjaneyulu, Assoc. Prof, EEE Dept

R. Hothri, Asst. Prof, EEE Dept, TEC

Sk. Johny Begam, Asst. Prof, EEE Dept, TEC

P. Bhramaramba Vathi, Asst. Prof, EEE Dept, ESWR

K.Chandrika, Asst. Prof, EEE Dept, klmd

T.Venkatesh, Asst. Prof, EEE Dept, talasila
DIBC Double Inductor type Boost Converter

ICBC Inter Connected Boost Converter

UPQC Unified Power Quality Conditioner

UPQC is mixing of both series type, shunt type active power filters and in between these a unique DC Capacitor link. These active type power filters have separate operations. Series type filters is operated at regulated voltage value to minimize also to separate the voltage variations and shunt type filters act as a regulated current value to reduce current variations. The functional operation diagram of the UPQC is given in the following Fig.1.

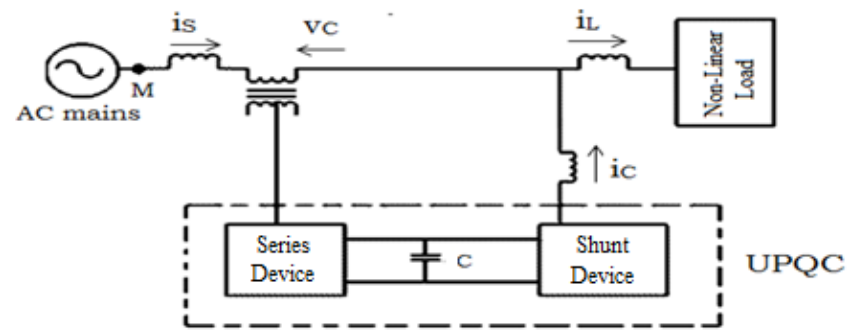

Figure 1: Functional Operation diagram of UPQC

\section{CONVENTIONAL UPQC CONFIGURATION}

Operational picture of Conventional UPQC system is given in Fig.2. In this figure a capacitor is placed across UPQC. A large battery is used to charge the capacitor of UPQC.

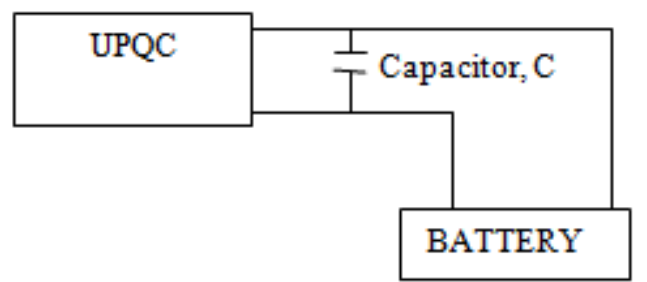

Figure 2: Operational Picture of Conventional UPQC Configuration

\section{PROPOSED BOOST CONVERTER FED UPQC SYSTEM}

Operational picture of proposed Boost Converter fed UPQC configuration diagram is given in Fig.3. Hence the converter between PV system and Capacitor matches the voltage of PV system with capacitor voltage of Unified Power Quality Conditioner (UPQC).

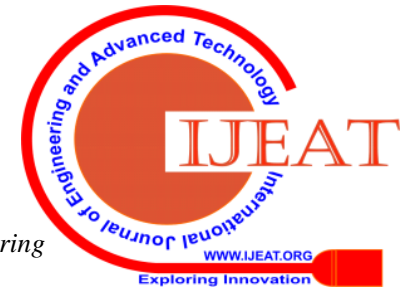




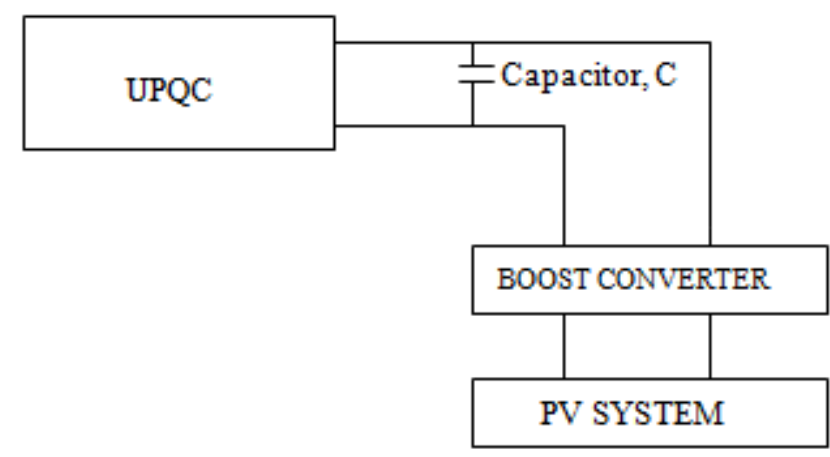

Figure 3: Operational picture of Proposed Boost Converter fed UPQC Configuration

\section{IMPLEMENTATION OF PROPOSED BOOST CONVERTERS FED UPQC SYSTEM}

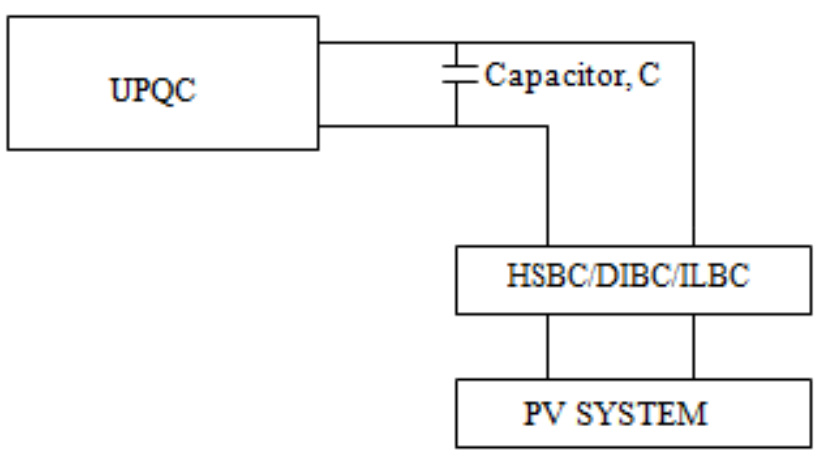

Figure 4: Implementation of HSBC/DIBC/ICBC fed UPQC System

This section describes the incorporation of UPQC system with one of boost converters like High Step Up type Boost Converter (HSBC), Double Inductor type Boost Converter (DIBC), Inter Leaved Boost Convertors (ICBC). The aim of this section is to selection of suitable boost converter between PV System and DC unique capacitor of UPQC.

Implementation of proposed system is given in the Fig.4. Receiving end voltage at $\mathrm{PV}$ is boosted using one of converters like HSBC/DIBC/ICBC. The capacitor of UPQC is charged by the output of HSBC/DIBC/ICBC.

\section{DESIGN WITH MATLAB/SIMULINK \& RESULTS COMPARATIVE ANALYSIS}

The successive concepts show that HSBC/DIBC/ICBC based UPQC system and its implementation in MATLAB/SIMULINK. Their MATLAB/SIMULINK results are analyzed and compared. The comparison is done in terms of boost converter output voltage ripple, input current ripple, real and reactive powers delivered from UPQC based Boost converter to the receiving end.

\section{5. a. HSBC based UPQC System \& MATLAB/SIMULINK Implementation}

High Step Up type Boost Converter is modeled at MATLAB/SIMULINK its circuit is given in Fig.5.a.1. This High Step Up type Boost Converter is incorporated in UPQC system, its MATLAB/SIMULINK implementation of HSBC based UPQC system is given in Fig.5.a.2.

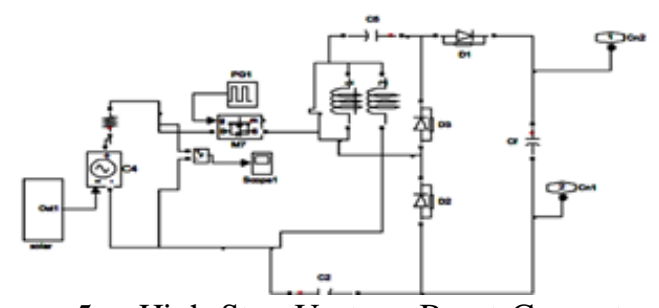

Figure 5.a. High Step Up type Boost Converter modeled Circuit

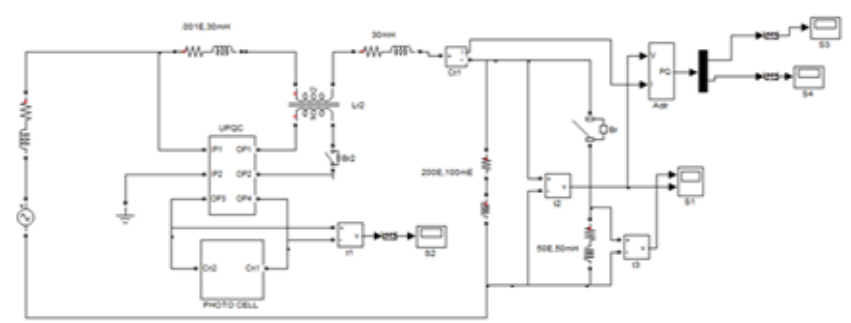

Fig.5.a.2. UPQC with High Step Up type Boost Converter MATLAB/SIMULINK Circuit

The input current ripple of HSBC is given in Fig.5.a.3 and its maximum value is 18 Amperes. The receiving end voltage of HSBC is given in Fig 5.a.4 and its shows the value is 400 Volts. The receiving end ripple value of voltage of HSBC is given in Fig.5.a.5 and it has a maximum value of 425 Volts. Real power delivered from HSBC based UPQC system is given in Fig.5.a.6 and its value is $3 * 10^{5}$ Watts. Reactive power delivered from HSBC based UPQC system is given in Fig.5.a.7 and its value is $6^{*} 10^{5}$ VAR. The enhancement in real and reactive powers is because of the adding voltage by High Step Up type Boost Converter in UPQC based system.

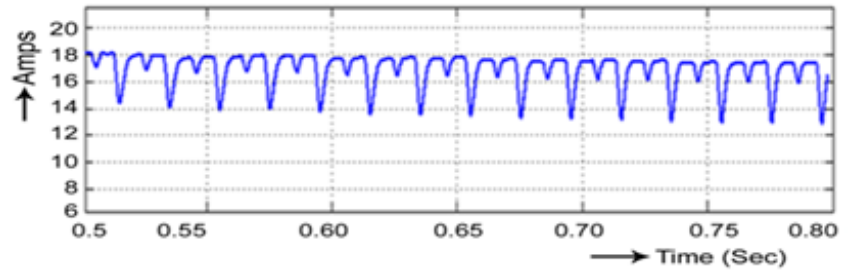

Fig.5.a.3. Input Current Ripple in HSBC

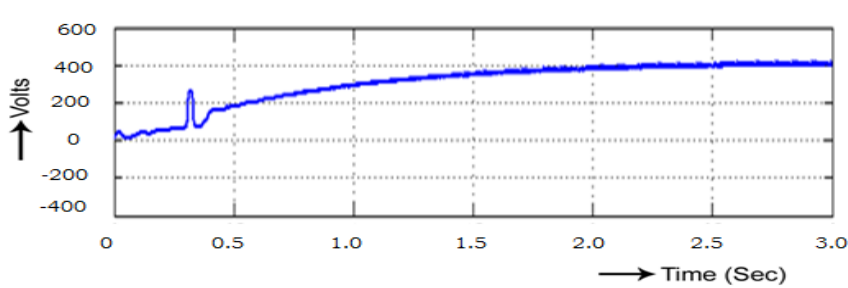

Fig.5.a.4. Receiving end Voltage at HSBC

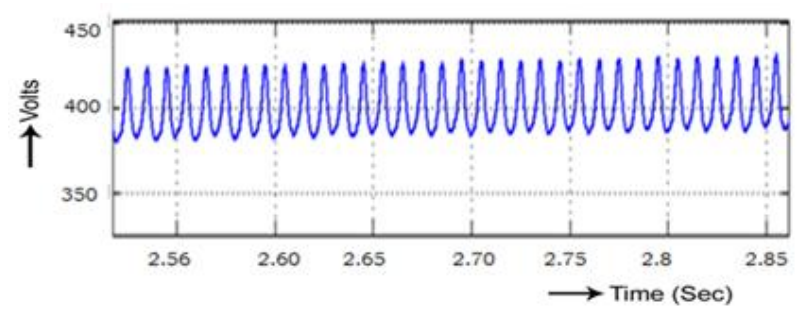

Fig.5.a.5. Receiving end Voltage in HSBC 


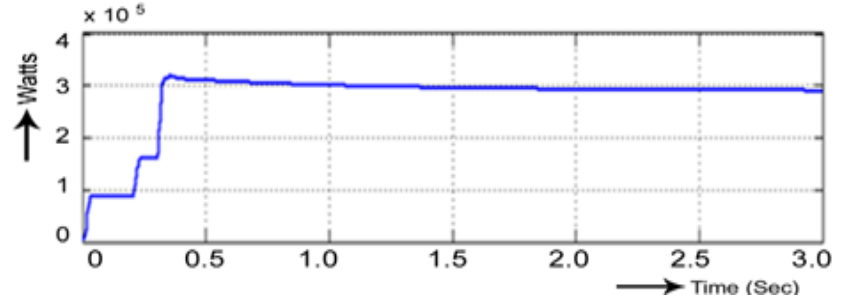

Fig.5.a.6 Real Power of Receiving End at HSBC based UPQC

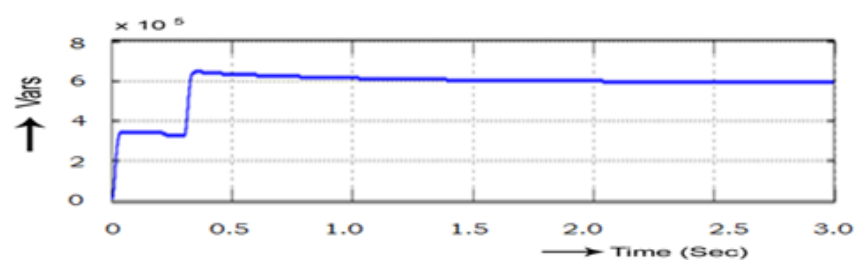

Fig.5.a.7. Reactive Power of Receiving End at HSBC based UPQC

\section{5. b. DIBC based UPQC System \& MATLAB/SIMULINK Implementation}

Double Inductor type Boost Converter is modeled at MATLAB/SIMULINK its circuit is given in Fig.5.b.1. This Double Inductor type Boost Converter is incorporated with UPQC system and its MATLAB/SIMULINK Implementation of DIBC based UPQC system is given in Fig.5.b.2.

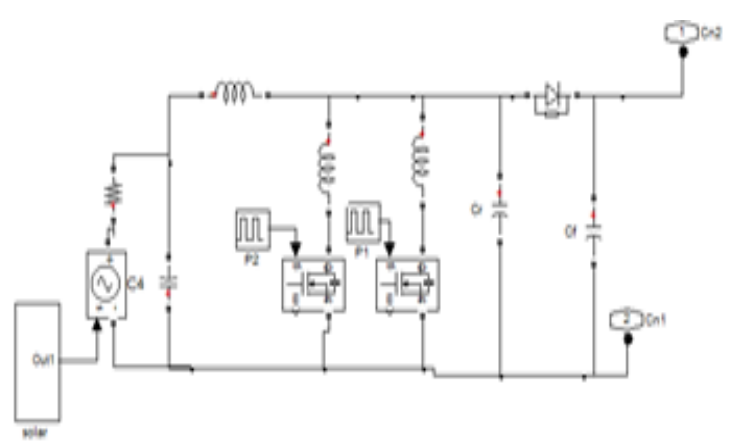

Fig.5.b.1. Double Inductor type Boost Converter modeled circuit

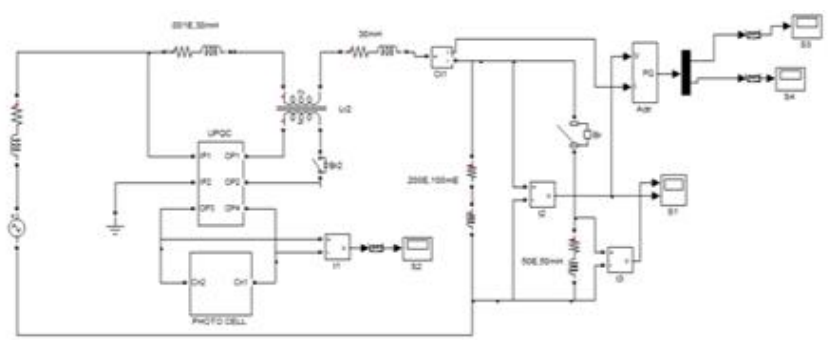

Fig.5.b.2. UPQC with Double Inductor type Boost Converter MATLAB/SIMULINK circuit

DIBC produces the required voltage to charge the capacitor. Simulation results are shown in the following figures. The input current ripple of DIBC is given in Fig.5.b.3 and its maximum value is 19.5 Amps. The receiving end voltage of DIBC is given in Fig.5.b.4 and its shows the value is 750 Volts. Receiving end ripple voltage DIBC is given in Fig.5.b.5. The real power delivered from DIBC based UPQC system is given in Fig.5.b.6 and its value is $3.7 * 10^{5}$ Watts The reactive power delivered from DIBC based UPQC system is given in Fig.5.b.7 and its value is $6.9 * 10^{5}$ VAR.

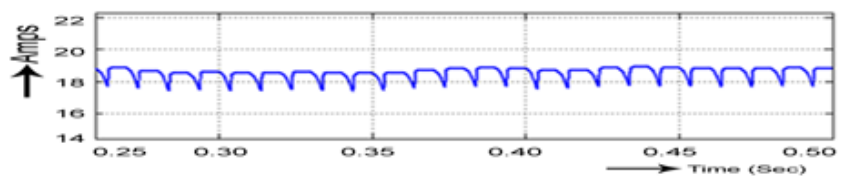

Fig.5.b.3. Input Current Ripple of DIBC

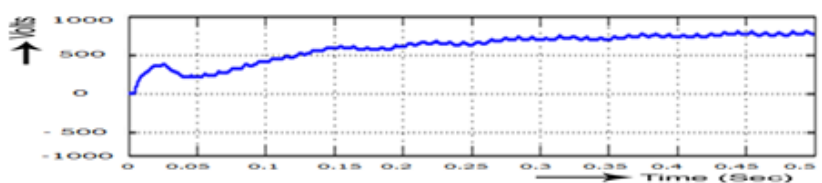

Fig.5.b.4. Receiving end Voltage of DIBC

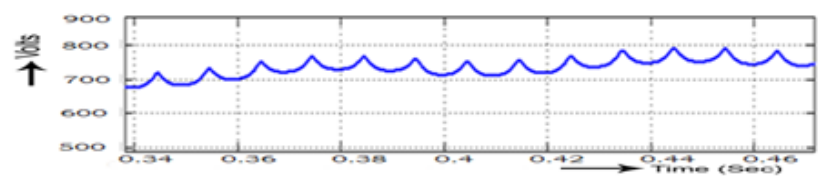

Fig.5.b.5. Receiving end Voltage of DIBC

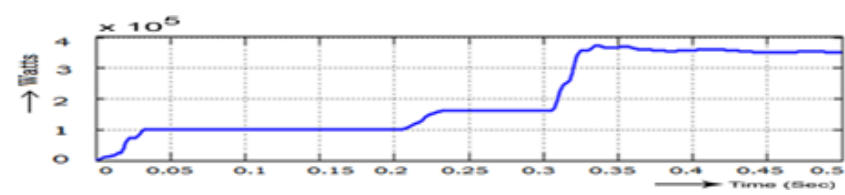

Fig.5.b.6. Real Power at Receiving End of DIBC based UPQC

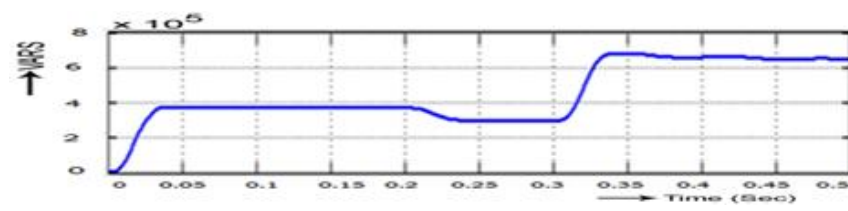

Fig.5.b.7. Reactive Power at Receiving End of DIBC based UPQC

\section{5. c. ICBC based UPQC System SIMULINK Implementation}

The Inter Connected Boost Converter (ICBC) fed UPQC system is simulated in SIMULINK/MATLAB. Here the voltage required for capacitor is supplied from Inter Connected Boost Converter (ICBC) with PV. Simulation results are analyzed in the following sections. ICBC modeled system is given in Fig.5.c.1. The UPQC with Inter Connected Boost Converter (ICBC) based system is given in Fig.5.c.2.

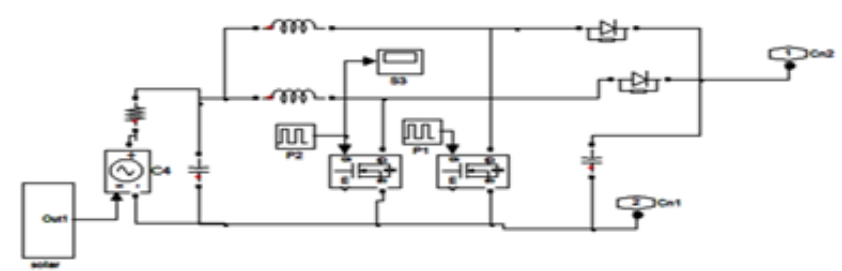

Fig.5.c.1. Inter Connected Boost Converter modeled circuit

Published By:

Blue Eyes Intelligence Engineering 


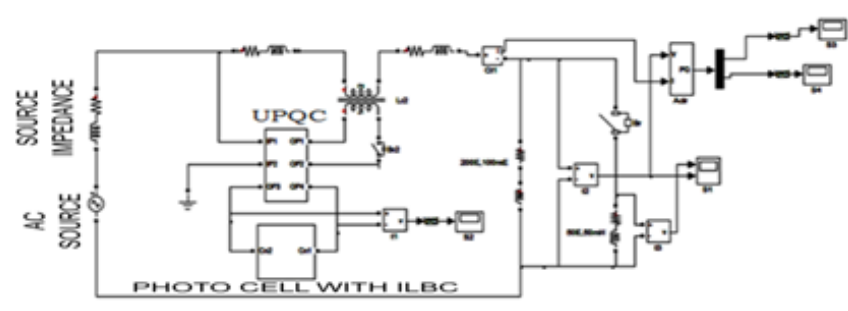

Fig.5.c.2. UPQC with Inter Connected Boost Converter

The input current ripple of ICBC based UPQC configuration is given in Fig.5.c.3 and its maximum value is 23.5Amps. Receiving end voltage of ICBC based UPQC is given in Fig.5.c.4 and its shows the value 1100 Volts. Receiving end ripple voltage of ICBC based UPQC is given in Fig.5.c.5 and its peak value is 1100 Volts. The real power delivered from ICBC based UPQC is given in Fig.5.c.6 and its value is $4 * 10^{5}$ Watts. The reactive power delivered from ICBC based UPQC is given in Fig.5.c.7 and its value is $7.5^{*} 10^{5} \mathrm{VAR}$. The increase in value at 0.2 seconds is due to increase in load. The increase in value at 0.3 seconds is due to the adding of voltage.

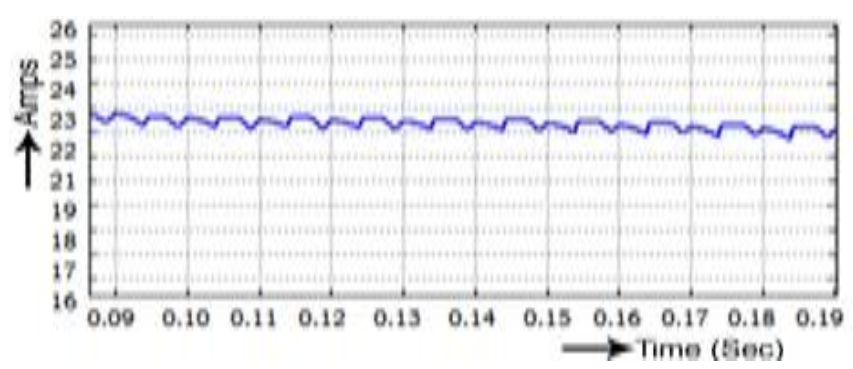

Fig.5.c.3. Input Current Ripple of ICBC

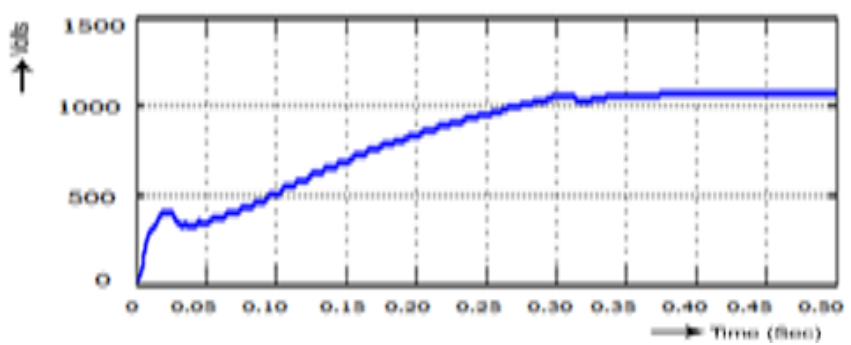

Fig.5.c.4. Receiving end Voltage of ICBC

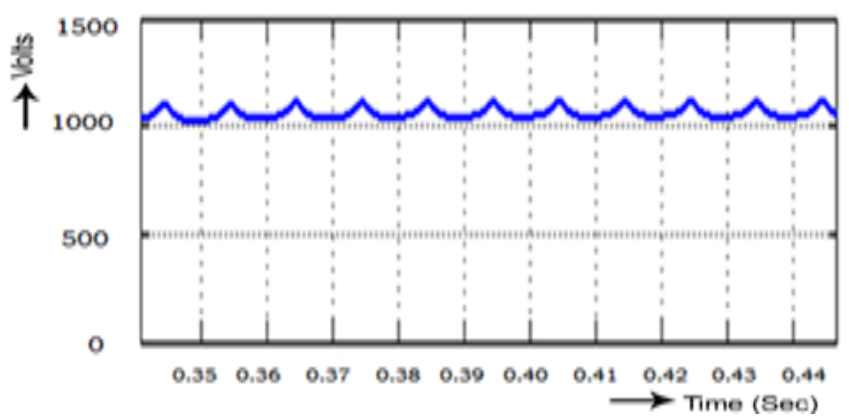

Fig.5.c.5. Receiving end Voltage of ICBC

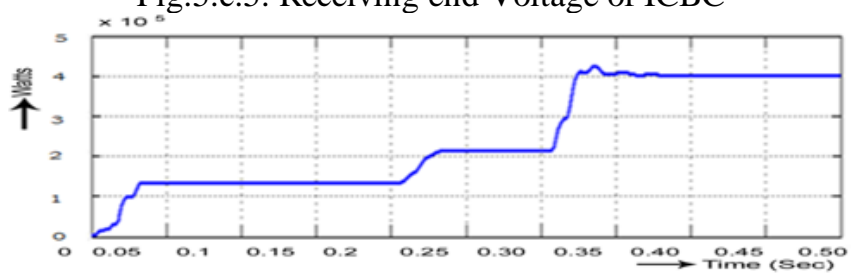

Fig.5.c.6. Real Power of Receiving End of ICBC based UPQC

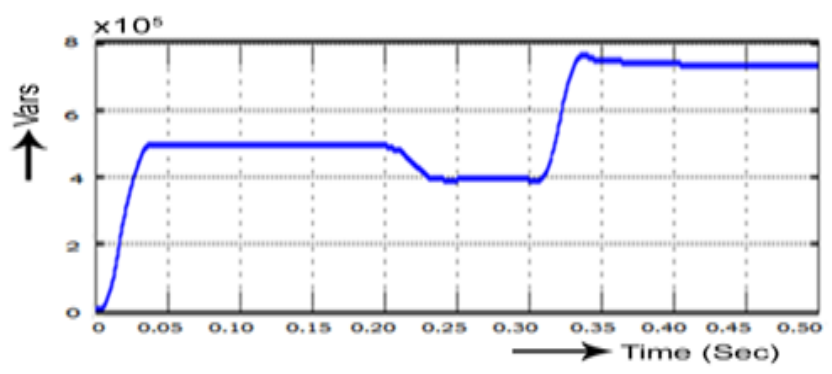

Fig.5.c.7. Reactive Power of Receiving End at ICBC based UPQC

Comparison of real and reactive powers with High Step Up type Boost Converter (HSBC), Double Inductor type Boost Converter (DIBC) and Inter Connected Boost Converter (ICBC) are given in the following Table - 5.a. The receiving end real power in Inter Connected Boost Converter (ICBC) based system is 0.039 Mega Watts more than Double Inductor type Boost Converter (DIBC) based system and 0.096MW more than High Step Up type Boost Converter (HSBC) based UPQC system. The receiving end reactive power in Inter Connected Boost Converter (ICBC) based system is 0.087 Mega Volta Ampere Reactive more than Double Inductor type Boost Converter (DIBC) based system and 0.123 Mega Volta Ampere Reactive more than UPQC based system. Real power, Reactive powers are high with Inter Connected Boost Converter (ICBC) based UPQC system.

Comparison of converter receiving end voltage ripple, input current ripple are given in Table - 5.b. Vor represents ripple content in the receiving end voltage of converter and IIr represents ripple content in the sending current of converter. The receiving end voltage ripple in ICBC based system is 17 Volts less than compared to DIBC based system and 22 Volts less than HSBC based UPQC system. The sending end current ripple in ICBC system is 0.5Amperes less than compared to DIBC based system and 1.6 Amperes less than HSBC based UPQC system. Ripple voltage and ripple current are minimum with ICBC based UPQC system.

Table - 5.a Comparison of Real and Reactive powers with HSBC, DIBC and ICBC systems

\begin{tabular}{|c|c|c|}
\hline \multirow{2}{*}{ UPQC } & $\begin{array}{c}\text { REAL } \\
\text { POWER } \\
(\text { MEGA } \\
\text { WATTS })\end{array}$ & $\begin{array}{c}\text { REACTIVE } \\
\text { POWER } \\
(\text { MEGA VOLT } \\
\text { AMPERE } \\
\text { REACTIVE })\end{array}$ \\
\hline $\begin{array}{c}\text { UPQC WITH } \\
\text { HSBC }\end{array}$ & 0.367 & 0.602 \\
\hline UPQC WITH DIBC & 0.364 & 0.638 \\
\hline UPQC WITH ICBC & 0.403 & 0.725 \\
\hline
\end{tabular}

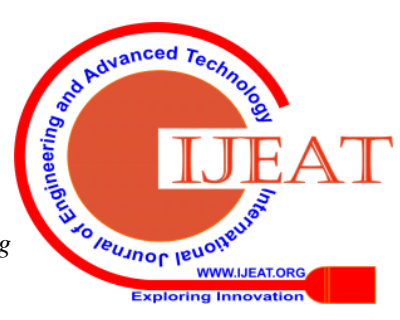


Table - 5.b Comparison of Converter Output Voltage Ripple and Input Current Ripple with HSBC, DIBC and ICBC

system

\begin{tabular}{|c|c|c|}
\hline UPQC & $\mathbf{V}_{\text {Or }}$ & $\mathbf{I}_{\mathbf{I r}}$ \\
\hline HSBC & 30 VOLTS & 2.2 Amperes \\
\hline DIBC & 25 VOLTS & 1.1 Amperes \\
\hline ICBC & 8 VOLTS & 0.6 Amperes \\
\hline
\end{tabular}

\section{CONCLUSION}

This work has reviewed various converters for UPQC systems. HSBC, DIBC and ICBC controlled UPQC systems are designed and modeled at MATLAB/SIMULINK; the results are had been given. The simulation results indicate that Inter Connected Boost Converter (ICBC) fed UPQC system produces voltage ripple of $8 \mathrm{~V}$ and current ripple of $0.6 \mathrm{~A}$.

Real power, Reactive powers delivered at receiving end are increased by $9.95 \%$ with respect to DIBC based UPQC system and $24 \%$ with respect to HSBC system. Therefore Inter Connected Boost Converter (ICBC) based UPQC is preferred to other systems to enhance power quality issue. Disadvantage with Double Inductor type Boost Converter (DIBC) and Inter Connected Boost Converters (ICBC) is that their hardware count is doubled.

\section{REFERENCES}

1. A. Banerji, S. K. Biswas, B. Singh, "DSTATCOM Control Algorithms: A Review," International Journal of Power Electronics and Drive System (IJPEDS), Vol.2, No.3, September 2012, PP. 285-296.

2. Mehmet Ucar and Engin Ozdemir, "Control of a 3-phase 4-leg active power filter under non-ideal mains voltage condition," Electric Power Systems Research 78 (2008): PP.58-73.

3. Srinivas Bhaskar Karanki, Mahesh K. Mishra,B. Kalyan Kumar,"Particle Swarm Optimization Based Feedback Controller for Unified Power-Quality Conditioner", "IEEE Transactions on Power Delivery, vol. 25, no. 4, October 2010: PP. 2814 - 2824 ".

4. Vasudhra Mahajan, Pramod Agarwal, Hri Om Gupta "Simulation of shunt active power filter using Instantaneous Power Theory" IEEE conference on Applied Power Electronics: 19-22, Dec. 2012.

5. Matin Kesler, Angin Ozadmir, "Synchronous Reference Frame based Control method of UPQC under balanced and distorted load conditions", IEEE Transactions on Industrial Electronics, vol.58, no.9, sep 2011.

6. Bhim Singh, Kamal Al-Haddad and Ambrish Chandra , "A Review of Active Filters for Power Quality Improvement" IEEE Transactions on Industrial Electronics, Vol.46, No.5, oct 1999: PP. 960-971.

7. Fang Zheng Peng,and Jih-Sheng, "Generalized Instantaneous Reactive Power Theory for Three phase Power Systems" IEEE Transactions on Instrumentation and Measurement, vol. 45, no. 1, February 1996: PP. 293-97.

8. Yash Pal, A. Swarup, Bhim Singh, "A control strategy based on UTT and Ic of three-phase, fourwire UPQC for power quality improvement" International Journal of Engineering, Science and Technology, Vol. 3, No. 1, 2011: PP. 30-40.

9. Metin Kesler and Engin Ozdemir, “A Novel Control Method for Unified Power Quality Conditioner(UPQC ) Under Non-Ideal Mains Voltage and Unbalanced Load Conditions," IEEE Conference on Applied Power Electronics, Feb. 2010: PP. 374-379.

10. Sai Shankar, Ashwani kumar and W.Gao "Operation of Unified Power Quality Conditioner under Different Situation,” IEEE Proceedings Power and Energy Society General Meeting, July 2011, 21: PP. 1-10.

11. Chellali Benachaiba, Brahim Ferdi "Voltage Quality Improvement Using DVR,” Electrical Power Quality and Utilization, Journal Vol. XIV, No. 1, 2008: PP. 39-46.
12. Rao, B. Venkateswara, et al. "Optimal power flow by Newton method for reduction of operating cost with SVC models." 2009 International Conference on Advances in Computing, Control, and Telecommunication Technologies. IEEE, 2009

13. S, Kanagavalli, Ajith Kumar M, Sarath Kumar M, Selva Murugan r, and Ram Kumar M. "Plc Based Automatic Cooling Of Power Transformer." international journal of communication and computer technologies 7.supplement 1 (2019), 38-41. Print. Doi:10.31838/ijccts/07.sp01.10 